Volume: 2 | Volumen 2 | Número 2 | Number 2 | pp. 123 - 134 ISSN: 2634-355X (Print) | ISSN: 2634-3568 (Online) journals.tplondon.com/yeiya

First Submitted: 15 December 2021 Accepted: 16 December 2021

TRANSNATIONAL PRESS ${ }^{\circledR}$ DOI: https://doi.org/10.33182/y.v2i2.2058

\title{
Redes de cuidado frente al entrampamiento migratorio por COVID-19 en México
}

\author{
Héctor Parra García ${ }^{1}$
}

\section{Resumen}

Este articulo analiza las redes de colaboración y proximidad que han surgido a través de la movilidad colectiva de las caravanas migrantes que transitan por México desde octubre de 2018. A partir de una breve genealogía del origen de estas caravanas y de los renovados procesos por contenerlas por parte de los gobiernos de México y Estados Unidos, se muestra la importancia de la resignificación de los lugares de arribo y las redes de solidaridad que se han consolidado por los numerosos tránsitos que han sucedido a la primera caravana centroamericana de 2018. Esta investigación pone énfasis en la importancia de las redes de cuidados de/por/para migrantes como un dispositivo que interpela el "entrampamiento migratorio" que padecen diversos colectivos migrantes en territorio mexicano y que evidencia la influencia de la demanda estructural de cuidados en Estados Unidos en el aumento de estas migraciones.

Palabras clave: Redes de cuidado; entrampamiento migratorio; migraciones centroamericanas; caravanas; Centroamérica

\section{Care networks against immigration entrapment by COVID-19 in México}

\begin{abstract}
This article analyzes the networks of collaboration and proximity that have emerged through the collective mobility of migrant caravans that transit through Mexico since October 2018. Based on a brief genealogy of the origin of this caravans and the renewed processes to containing them by the governments of Mexico and the United States, the importance of the resignation of the places of arrival and the networks of solidarity that have been consolidated by the numerous transits that have happened to the first Central American caravan of 2018 is shown. This research emphasizes the importance of/ by/for migrants' care networks as a device that challenges the "migratory entrampment" (Parra, 2020). It was evident that the structural demand for care in the United States was a factor in the increase in these migrations.
\end{abstract}

Keywords: Care networks; migratory entrapment; Central American migrations; caravans; Central America

\section{Introducción}

En las últimas décadas han surgido diversas migraciones provocadas por desastres naturales, violencias de Estado y despojos territoriales, generando movilidades cada vez más continuas y de mayores dimensiones a nivel global. El éxodo de sirios por toda la región balcánica en

\footnotetext{
${ }^{1}$ Mexicano. Doctor en Estudios Latinoamericanos por la Universidad Nacional Autónoma de México (UNAM), México. Actualmente es Profesor e Investigador Postdoctoral del Centro de Estudios Latinoamericanos, Facultad de Cienias Políticas y Sociales de la UNAM, México. Correo electrónico: h.parra.garcia@comunidad.unam.mx.
} 
Europa o la diáspora haitiana provocada por el terremoto en 2010, son algunos ejemplos de ello.

La respuesta de los países del Norte Global a estos crecientes flujos de personas ha sido la implementación de políticas migratorias cada vez más contenciosas, vinculando a la migración como un problema de seguridad interna y delegando a terceros países el control de las migraciones que van hacia sus territorios. Un ejemplo muy reciente lo encontramos en las amenazas arancelarias de la administración de Donald Trump para obligar al Gobierno de México a cambiar radicalmente sus políticas migratorias hacia mayores detenciones y trabas burocráticas hacia los migrantes que transitan por el país.

Estas experiencias, -que se replican en el contexto de la Unión Europea- han reconfigurado el "régimen global de fronteras" (Mezzadra, 2012), ya que incorpora nuevas tecnologías de violencia a la gestión contenciosa de la migración. La terciarización de las fronteras en países del sur global ha configurado una versión necrótica de este régimen global de fronteras, donde el continuum de violencia hacia los migrantes -sobre todo hacia el cuerpo de las mujeresrepresenta una fuente extraordinaria de plusvalía para el crimen organizado y para funcionarios corruptos.

Las versiones gore (Valencia, 2010) en terceros países de este régimen global de fronteras ha ocasionado que las estancias no planeadas de los migrantes se prolonguen cada vez más, generando que los migrantes se queden "atrapados en el tránsito" (Hess, 2012). Esta realidad global, supone nuevos retos en los estudios de la migración, ya que muestra nuevas dimensiones a la realidad migratoria como son las gestiones de las esperas y las redes de cuidado que sostienen la vida durante estos entrampamientos.

Ante este escenario, este artículo recorre las diversas estrategias de subsistencia y solidaridad que diversos colectivos migrantes - principalmente provenientes de Centroamérica- que transitan por México han desarrollado para evitar su entrampamiento en distintas ciudades del territorio mexicano. A partir de una revisión documental y hemerográfica, resaltamos la importancia de desarrollar nuevas interpretaciones de las migraciones centroamericanas en su tránsito por México, sobre todo haciendo hincapié en la capacidad de agencia y autonomía de los migrantes como actores de los despojos y las violencias territoriales del siglo XXI.

El artículo transcurre en tres momentos, en primer lugar, se presenta - a modo de constructo teórico- la importancia de la perspectiva de la autonomía de las migraciones para comprender las complejas tramas de la migración transnacional en la región y las redes de cuidado que interpelan el entrampamiento migratorio que ha ido consolidando el régimen de fronteras en su versión necrótica en el territorio mexicano. Así, se problematizan dimensiones de esta realidad migratoria como son las esperas, el entrampamiento migratorio y los cuidados. En un segundo momento se presenta una breve genealogía de las migraciones centroamericanas poniendo énfasis en su etapa transnacional. Este último periodo se configura a raíz de los vínculos de proximidad entre los lugares de origen y destino, así como por la demanda estructural de cuidados que requiere mano de obra feminizada en distintas ciudades de la Unión Americana. En un tercer apartado se describen las principales estrategias de cuidado que han soportado las caravanas que transitan por México, y cómo dichas estrategias han logrado resignificar ciertos lugares de arribo que se han convertido como referentes para futuras caravanas. De esa manera, se proyecta cómo estas estrategias de cuidados -que mantienen resonancia con la circularidad de estos flujos migratorios- interpelan el actual 
escenario de entrampamiento migratorio que ha causado la gestión migratoria por parte del Gobierno de México, con el programa “Quédate en México", así como por el cierre de fronteras entre México y Estados Unidos y la consecuente paralización de solicitudes de asilo por parte de las administraciones norteamericanas de Donald Trump y de Joe Biden.

\section{Autonomía y cuidados frente el entrampamiento migratorio}

A partir de un estudio de los desplazamientos forzados por la guerra de los Balcanes en la década de 1990, Sabine Hess planteó la importancia de problematizar el largo periodo de tiempo que supone el tránsito de migrantes desde el punto de origen hasta el de destino. Hess acuñó el concepto de "atrapados en la movilidad" (2012) para romper con la idea generalizada de que las migraciones se dan de un lugar de origen hacia otro de destino, lo que resulta fundamental en el estudio de las relaciones y vínculos que se generan en este entrampamiento de migrantes.

En esta misma década surgieron diversos estudios que problematizaron el tránsito migratorio, entendiéndolo como un proceso que podía prolongarse a través de múltiples espacios y a lo largo de muchos años. En el caso de México, se llevaron a cabo algunos estudios sobre la migración centroamericana, sus formas de movilidad, las rutas, sus redes de apoyo y las políticas migratorias en que se enmarcan (Anguiano, 2007; Castillo y Palma, 1999). Dado el contexto de violencia y de endurecimiento de las políticas migratorias tanto de México y Estados Unidos, la migración centroamericana va adquiriendo una tendencia de migración por etapas, lo que implica una permanente construcción y reconstrucción de los proyectos migratorios.

La dimensión de la espera cobra relevancia en este nuevo escenario de entrampamiento migratorio. La espera se convierte en una relación de poder institucional con la que los Estados buscan contener a cuentagotas el flujo migratorio. Tenemos por ejemplo que en el momento más álgido de la pandemia (mayo de 2021), el Servicio de Aduanas y Migración de Estados Unidos admitió sólo 60 solicitudes de asilo en el puesto fronterizo de Tijuana-San Diego, generando de facto un estancamiento de personas en la franja fronteriza del norte de México (Del Monte y Mckee, 2020: 4). La gestión de las esperas se convirtió en un elemento de análisis muy importante ya que supone una tarea central en la vida cotidiana de las personas atrapadas en el tránsito. Los cuidados entre los propios migrantes, así como las relaciones de solidaridad de la sociedad civil se volvieron esenciales para sortear estas actividades adicionales de espera.

A pesar de estos escenarios de violencia y de contención, han surgido distintas formas de organización que interpelan este entrampamiento migratorio a nivel global. A través de variadas estrategias de resistencia y sobrevivencia se ensayan prácticas colectivas de solidaridad y de intercambio de favores para conformar circuitos migratorios cada vez más complejos y cohesionados. Estos vínculos cooperativos nos llevan a repensar en nuevas perspectivas que pongan en el centro del análisis la autonomía de las prácticas de los migrantes, en tanto que se ensayan nuevas formas de agenciamiento social.

Desde comienzos del siglo XXI surge un enfoque alternativo sobre el estudio de las migraciones que da prioridad de análisis a la capacidad de acción y de resistencia de sus protagonistas. El concepto de "autonomía de la migración” (2002) propuesto por Nicolás de Génova, surgió como una categoría-acción que reivindicaba la producción de conocimiento 
a partir de las prácticas cotidianas y resistencias de los migrantes. Diversas investigaciones que surgieron a la luz de esta perspectiva -sobre todo en el sur de Europa- coincidieron en la necesidad de virar hacia una agenda de investigación de las luchas y resistencias de los migrantes en su ejercicio radical de ciudadanía. Asumir la migración como un proceso autónomo y una fuerza irreductible, capaz de sobreponerse a la rigidez de su control, conllevó a Sandro Mezzadra a extrapolar dicha fuerza de la migración como un anclaje prefigurativo de la historia del capitalismo. Mezzadra (2007) plantea que la historia del capitalismo es parte también del resultado de las luchas y tensiones que se producen por la "valorización" y la "contención" de la movilidad de la mano de obra, y cómo estas subversiones conforman subjetividades (modos de vida, deseos, hábitos) que pueden interpelar las sujeciones de la población "en exceso" en el régimen de acumulación capitalista.

Desde estas premisas es importante visibilizar las potencias creativas y activas de las migraciones que surgen de la interacción -e interpelación- hacia las distintas contenciones hacia su movilidad. Las caravanas migrantes de centroamericanos a su paso por México son quizás, el ejemplo reciente de mayor envergadura. Antecedidas por otros ejercicios de activismo migrante (caravanas de madres de desaparecidos, viacrucis migrante, acompañamientos pastorales, etcétera), las caravanas han supuesto una estrategia masiva de "autocuidado colectivo" (Glockner, 2019) donde las redes digitales han jugado un papel central.

Se pone énfasis en las redes de cuidado como una dimensión clave en la autonomía de las migraciones, y particularmente en estas experiencias de movilidad colectiva. Podemos entender por cuidados toda actividad -mayoritariamente no reconocida y realizada por mujeres- que sostiene y preserva la vida de otros. Estos trabajos devienen en vínculos materiales y afectivos sin los cuales no puede ser posible la reproducción de las sociedades. Existen investigaciones feministas (Glenn, 2010; Tronto, 2007) que sugieren retomar la idea de los cuidados desde una perspectiva integral, resaltando el potencial político que existe detrás de estas actividades por el sostenimiento de la vida.

En términos políticos y éticos, la dimensión de los cuidados expone la condición de vulnerabilidad de la vida -tanto humana como no humana- la cual debe ser reproducida y sostenida bajo la responsabilidad colectiva de unos por otros. Sin cuidados no puede existir la sociedad, por lo que debemos concebir dichas actividades como un campo de acción y de identidad política por parte de quienes las protagonizan. Una lucha colectiva que interpela su invisibilidad y su asignación casi naturalizada hacia las mujeres y su desvalorización en el marco de las sociedades globales.

En el escenario migratorio que caracterizamos en este artículo, la dimensión de cuidados se refleja en dos sentidos. En primer lugar, la dimensión de cuidado cobra relevancia en el tránsito de las caravanas migrantes, en tanto que la colectivización de los cuidados permitió el tránsito de personas vulnerables, pero además permitió la agencia política entre los migrantes al evidenciar que es posible migrar de manera colectiva, organizada y segura por uno de los lugares de tránsito más peligrosos del mundo. En segundo lugar, los cuidados y su estructura en los países del norte global, han configurado un incesante flujo de trabajos feminizados del cuidado, provocando circularidades migratorias debido a la conformación de familias transnacionales, donde las mujeres son protagonistas. Volveremos a ello en el tercer apartado. 


\section{Genealogía del transnacionalismo migratorio en Centroamérica}

Las migraciones centroamericanas han consolidado una expertise migratoria, producto de diversos flujos y reflujos de personas que han migrado a lo largo de más de tres generaciones hacia Estado Unidos. Este saber-hacer migratorio se ha conformado de distintos repertorios culturales (vínculos familiares, información, contactos, etcétera), que operan en varios niveles de acción, siendo los principales recursos con que cuentan los migrantes. En el caso de las caravanas migrantes más recientes, estas fueron posibles gracias a diversos capitales culturales previos, es decir, un cúmulo de distintas redes informales de contactos personales, de vínculos familiares, de relaciones de proximidad y del conocimiento que se tiene del lugar de destino. Dicho saber-hacer migratorio se ha transmitido de manera intergeneracional, siendo quizás las experiencias más indelebles los éxodos forzados en los periodos de mayor convulsión social y política de las décadas de 1970 y 1980.

A nivel económico existen varias causales estructurales que han detonado el flujo de migrantes centroamericanos, principalmente hacia Estados Unidos y México. Las economías de Guatemala, El Salvador, Honduras y Nicaragua han producido de manera histórica una fuerza de trabajo excedente, tanto en el sector rural como en el urbano, debido a la incapacidad de ser absorbidas por las estructuras de enclave y de alta especialización que prevalecen en los tres sectores económicos de todos los países de la región.

A inicios de la década de 1980 con la llegada de Ronald Reagan a la presidencia de Estados Unidos, hubo una intensificación de sus políticas intervencionistas en la región. Las políticas de seguridad nacional y de planeación económica fueron los sectores más intervenidos a partir de programas de asistencia empresarial y policial. Para muchos investigadores (Morales, 2007; Sandoval, 2015; Contreras, 2018), estas políticas de intervención marcan el auge del neoliberalismo en Centroamérica y con ello, el origen de los flujos migratorios que prevalecen en la actualidad.

Los desplazamientos forzados, producto de las intervenciones militares de Estados Unidos en El Salvador y Guatemala -que según Jenny Pearce se estima en 2 millones de desplazados (1998:590) - y el recrudecimiento de políticas económicas primario-exportadoras de enclave producto del ajuste económico estructural del periodo "democrático" (década de 1990)- en todos los países, fueron el antecedente de las actuales comunidades migrantes centroamericanas en Estados Unidos. Estos primeros éxodos -atravesados por diferencias de origen étnico-culturales, por brechas inter-generacionales y por escalas de tránsito- explican en gran medida la dinámica migratoria actual hacia Estados Unidos.

A comienzos del siglo XXI, la entrada en vigor de diversos acuerdos de libre comercio entre los países centroamericanos con Estados Unidos ocasionó un recrudecimiento de los niveles de pobreza y de desigualdad social, trayendo consigo un clima propicio para la expansión de grupos delictivos en toda la región. Estos grupos criminales se han transnacionalizado gracias a estas circularidades migratorias ${ }^{2}$ y han allanado el camino para la configuración de una

\footnotetext{
${ }^{2}$ La deportación de 250,000 centroamericanos que cumplían una sentencia judicial en Estados Unidos en la década de 1990, marcó el comienzo de una etapa transnacional de pandillas de origen centroamericano como son la Mara Salvatrucha y el Barrio 18. A pesar de que estas bandas han conectado a comienzos del siglo XXI con cárteles mexicanos y otros grupos criminales, su alcance transnacional se ha visto reducido a lo largo de los años a ciertos rasgos estéticos e identitarios. Para más detalles véase Santamaría Balmaceda (2007).
} 
economía criminal, basada en la extorsión generalizada y bajo la connivencia de los gobiernos nacionales centroamericanos.

Así, los actuales flujos migratorios se retroalimentan de la "trinidad perversa" (Varela, 2015) -es decir, la movilidad que surge a raíz de las violencias del mercado, del Estado y del sistema patriarcal- pero lo hacen también a partir de los vínculos de proximidad que han provocado los flujos y reflujos de migrantes centroamericanos hacia los principales lugares de asentamiento en la Unión Americana.

De acuerdo con estimaciones del Migration Policy Institute (MPI) la población total de centroamericanos en Estados Unidos se ha duplicado desde 1980 (354,000 migrantes en ese año), alcanzando la cifra de 3,782,000 en 2019 (Babich y Betalova, 2021), siendo 37\% $(1,412,000)$ salvadoreños, $29.4 \%(1,111,000)$ guatemaltecos, $19.7 \%(746,000)$ hondureños y 13.6\% (514,350) del resto de países de la región. La mayoría de los inmigrantes centroamericanos radican en California (25\%), Texas (12\%), Florida (11\%) y Nueva York (13\%). Los lugares de radicación son eminentemente metropolitanos, siendo Los Ángeles (16\%), Nueva York (11\%), Washington, D.C. (9\%), Miami y Houston (7\% cada una) las principales ciudades (Babich y Betalova, 2021).

La colectividad centroamericana en Estado Unidos es mayoritariamente trabajadora, al situarse en un $81 \%$ en la edad laboral de 18 a 65 años. Las principales ocupaciones son los servicios domésticos, de cuidado y personales (31\%), construcción y mantenimiento (25\%) y ocupaciones fabriles y transportes (19\%) (Babich y Betalova, 2021). El envío de remesas hacia Centroamérica se ha multiplicado por 7 desde 2000, alcanzando la cifra de 25,800 millones de dólares en 2020, representando 25\% del PIB en El Salvador y Honduras.

Todas estas cifras nos muestran la vitalidad del movimiento de personas centroamericanas y con ello de distintos vínculos cooperativos- entre los lugares de origen y destino. Esto supone que los flujos migratorios hacia Estados Unidos se han vuelto cada vez más indispensables en las economías de subsistencia familiar en la región, implicando a miembros cada vez más extensos de las familias y comunidades, generando tramas migratorias cada vez más complejas y cohesionadas.

Una dimensión que ha complejizado aún más estas tramas migratorias tiene que ver con el aumento de mujeres centroamericanas jefas de hogar que migran para trabajar en actividades del cuidado - mayoritariamente feminizados- cuya demanda se ha incrementado en los últimos años en Estados Unidos, debido a múltiples factores como el envejecimiento progresivo de su población y la incorporación de mujeres norteamericanas a actividades "productivas".

Esto conlleva un doble impacto en el ordenamiento de las obligaciones del cuidado de las familias en los lugares de origen. Debido a la ausencia de los "cuidados maternos", surgen diversos arreglos familiares -y en los círculos de proximidad-con la finalidad de transferir las tareas afectivas y materiales del cuidado hacia otras mujeres como madres, hermanas, primas o hijas o vecinas. Un segundo impacto tiene que ver con la vulnerabilidad de estos arreglos del cuidado y que, en numerosas experiencias generan un gradual deterioro en los vínculos familiares de origen, sobre todo cuando las estancias migratorias de las madres se prolongan en el tiempo.

Se produce un "dislocamiento en las relaciones de parentesco" (Ortega, 2015) desarticulando vínculos familiares y borrando la cercanía que se requiere para mantener relaciones afectivas. 
Las relaciones de cuidados que pueden generarse entre padres e hijos por medios electrónicos han tenido un alcance limitado y, sobre todo, se difuminan cuando los hijos crecen bajo el horizonte aspiracional de migrar cuando sean mayores.

\section{Redes de cuidado frente al entrampamiento migratorio en México}

En las últimas dos décadas el territorio mexicano se ha convertido en una "frontera vertical" (González, 2011) que cumple de forma necrótica la contención del tránsito migratorio de centroamericanos, contribuyendo así al régimen de fronteras que impone Estados Unidos, sobre todo desde 2014 con la "crisis de menores no acompañados" y el plan de securitización "frontera sur". Este proceso contencioso a la movilidad de migrantes ha provocado que diversas ciudades -sobre todo en las franjas fronterizas del sur y norte del país- acojan a migrantes a estancias temporales que pueden prolongarse incluso por años. Rebasa a los objetivos de este artículo desarrollar exhaustivamente las genealogías históricas del actual "entrampamiento migratorio" (Parra, 2020) de centroamericanos en territorio mexicano. No obstante, es importante señalar algunos momentos clave en la consolidación de este fenómeno, sobre todo en los últimos dos años de cierre de fronteras por la emergencia sanitaria por COVID-19. A continuación se muestra una breve crónica de los hechos más significativos en el entrampamiento migratorio de la franja fronteriza del norte de México:

Cuadro 1. Crónica del entrampamiento migratorio en México

El gobierno norteamericano de Barack Obama declara la "crisis humanitaria de menores no acompañados" con la cuál solicita al Congreso de Estados Unidos presupuestos extraordinarios

Junio de 2014 para la aplicación de políticas migratorias de corte securitista. Días después, la administración de Obama firma con el gobierno mexicano de Enrique Peña Nieto el "Plan Frontera Sur" por medio del cual se legitima la persecución y detención masiva de migrantes en territorio mexicano.

El gobierno norteamericano de Donald Trump implementa una política antiinmigrante de "cero tolerancia" donde se autoriza la separación familiar, la detención extrajudicial de niños y

Abril de 2018 adolescentes y la deportación de sus padres. Estas medidas - con un claro castigo a quienes intentan entrar a territorio estadounidense de forma ilegal- se incorpora como una "nueva estrategia de fronterización” (Glockner, 2021) que contribuye al entrampamiento migratorio de padres deportados en territorio mexicano.

La primera caravana migrante, que una semana antes fue convocada en San Pedro Sula (Honduras), llega a la frontera sur de México y se enfrenta a un operativo policial de Guatemala

Octubre de (Varela y Mc Lean, 2019). Este hecho da comienzo a la cobertura mediática de la migración 2018 centroamericana. El gobierno de Donald Trump aprovecha el impacto mediático de las caravanas -que tilda de invasión- para acentuar una política migratoria de "cero tolerancia" y de separación de las familias.

Con la finalidad de incidir que los migrantes que arriban en las caravanas centroamericanas se queden en México, el gobierno de Andrés Manuel López Obrador emite de manera masiva visas humanitarias y un plan regional de trabajo bajo el lema de "Quédate en México". Esta política de carácter humanitario se proyecta de manera permanente y provoca un "efecto llamada" a nuevas

Enero de 2019 caravanas (Ernst y Semple, 2019). El Gobierno de Estados Unidos implementa los Protocolos de Protección a Migrantes (MPP por sus siglas en inglés). Estos protocolos permiten que los migrantes que hayan entrado a Estados Unidos por México de manera ilegal o con documentos inadecuados, pueden ser retornados a México durante las resoluciones de sus solicitudes de asilo (USembassy, 2019). 
La política migratoria de carácter humanitario del Gobierno de México cambia radicalmente. En pleno contexto de la firma del TMEC, la administración de López Obrador sucumbió a las amenazas del gobierno de Donald Trump de que debería detener el flujo migratorio de Junio de 2019 centroamericanos a cambio de evitar una imposición arancelaria. Se despliega alrededor de 6 mil efectivos de la recién creada Guardia Nacional en la franja fronteriza del sur del país. A pesar de los discursos de una política migratoria abierta, el Gobierno de México perfila al país como un "tercer país seguro".

La OMS declara la pandemia por COVID-19 (11/03/2020). El 19 de marzo se emite un mandato de confinamiento en California (Estados Unidos). El 20 de marzo el gobierno de Donald Trump activa nuevos protocolos de deportaciones exprés. El 21 de marzo México y Estados Unidos

Marzo de 2020 acuerdan un cierre fronterizo para "viajes no esenciales". El 23 de marzo comienza "la jornada nacional de sana distancia” en México. El 24 de marzo se anuncia el primer aplazamiento de audiencias para MPP en las cortes judiciales de Estados Unidos. Se estima que para esa fecha, cerca de 60,000 migrantes se encuentran en las ciudades de la frontera norte de México a la espera de sus resoluciones de asilo (Del Monte y Mckee, 2020: 4)

La policía antidisturbios y el ejército de Guatemala dispersaron de manera violenta la primera caravana migrante organizada en 2021, la cual se estima que estaba integrada por 7 mil personas. Proveniente de Honduras, la caravana pretendía llegar a Estados Unidos, aprovechando la coyuntura del ascenso de Joe Biden a la presidencia de Estados Unidos. Se reportaron cientos de migrantes heridos y se confirmaron mil deportaciones de ciudadanos hondureños (González, 2021). Con esta contención, el gobierno guatemalteco cumple la función de país tapón, diseminando a lo largo de su territorio diversos retenes policiales y dejando un claro mensaje de que por su territorio no cruzarán más caravanas. Por otro lado, la ratificación de estas violentas contenciones, confirman la continuidad de una política migratoria de puertas cerradas por parte de la administración entrante de Joe Biden.

En la ciudad de Tapachula, Chiapas se concentran alrededor de 300,000 migrantes mayoritariamente centroamericanos y haitianos- a la espera de la resolución a sus solicitudes de asilo, condicionadas a su permanencia en este Estado de la frontera sur de México (Reina, 2021).

Septiembre de Muchas de estas esperas de resolución superan los 12 meses. El 24/09/2021 cerca de 17,000 2021 migrantes haitianos improvisaron un campamento en las ciudades fronterizas Acuña, Coahuila (México) y Rio Grande, Texas (estados Unidos). Dos días después los migrantes se retiran del campamento después de la persuasión de amplios dispositivos policiales en ambos lados de la frontera (Ramos y Chio, 2021).

El 23/10/2021 surge una nueva caravana migrante -conformada por miles de centroamericanos y haitianos- como respuesta a la política de desgaste que suponen las largas esperas para las resoluciones de asilo en la frontera sur del país. A pesar de los diversos retenes de la Guardia

Octubre de 2021 Nacional, la caravana continúa su camino hacia el norte de México bajo el escepticismo de que sean resueltas estas peticiones de asilo por parte del Instituto Nacional de Migración (INM). El 12/12/21 arriba la caravana a la Ciudad de México, bajo un dispositivo policial que les impide de manera violenta el libre tránsito hacia el centro de la ciudad.

Fuente: elaboración propia a partir de diversas fuentes periodísticas citadas

Este escenario de entrampamiento migratorio ha sido respondido con diversas experiencias de solidaridad. Estas caravanas mostraron múltiples estrategias de cuidados colectivos que representan formas de resistencia que los migrantes ya ensayaban en sus proyectos migratorios anteriores -como las caravanas de madres de migrantes de desaparecidos (2006) y los viacrucis migrantes (2011) - y que han consolidado una expertise clave en esta "caravanización de la transmigración” centroamericana (Varela, 2020).

La primera forma de resistencia -que a su vez comprende diferentes estrategias- fue la de sostener la vida durante el tránsito. Desde los pioneros ensayos de los viacrucis migrantes con una fuerte carga religioso-política, al extrapolar las migraciones actuales con los éxodos bíblicos- los primeros grupos caravananeros han ido consolidando durante sus 
desplazamientos, diversos referentes espaciales de ayuda y solidaridad que rebasan los exiguos albergues y comedores. Los lugares donde transitan las caravanas sirven de referencia para la distribución de víveres, así como para la organización en la obtención de alimentos, medicinas, hospedaje y protección. Sin estos espacios de referencia, resultaría muy difícil la migración de niños, adolescentes y ancianos, grupos vulnerables que se han incorporado de forma permanente a las migraciones actuales.

Sobrevivir caravaneando y resguardando la integridad de todos los caravaneros, supone una potencia política radical ya que pone en el centro del accionar colectivo a la preservación de las vidas más vulnerables. La perspectiva de género cobra relevancia ya que gran parte de la empatía radical que permite el accionar caravanero la generan madres solteras, abuelas y otras mujeres. Las redes de cuidado colectivo que surgieron a raíz de la convergencia de estos grupos generaron una nueva identidad migrante: el caravanero que migra colectivizando una diversidad de recursos materiales y simbólicos (dinero, víveres, contactos, favores, información, estrategias, etcétera).

La seguridad que genera la autodefensa colectiva es quizás el mayor estímulo para caravanear. En las primeras caravanas de 2018, no hubo secuestros ni extorsiones, sobre todo por la presencia permanente de los medios de comunicación, aunque las violencias se generaron en las siguientes caravanas por algunos cuerpos policiacos y funcionarios del INM.

Como antes señalamos, existe un profundo sincretismo entre los imaginarios religiosos mayoritariamente cristianos y católicos- y las caravanas. Las narrativas bíblicas, que equiparan las caravanas con los éxodos hebreos, han conformado simbolismos muy eficaces y comprensibles para legitimar el derecho inalienable de caravanear para sobrevivir. Así mismo, estas narrativas han configurado un ideario de comunidad en movimiento que ha servido de soporte psicológico y emocional a los miembros de las caravanas. Han permitido también la construcción de diversos horizontes comunes de esperanza, los cuales ayudan a hacer frente a las múltiples incertidumbres.

A nivel político, las caravanas representan un ejercicio radical de ciudadanía que muestra cómo los migrantes no están dispuestos a continuar transitando de forma clandestina e insegura por México. Surge de las caravanas distintas estrategias de denuncia colectiva a las responsabilidades de los gobiernos centroamericanos por las condiciones de desigualdad económica y violencia estructural que padece la mayoría de sus ciudadanos. Al incorporar la manifestación política, las narrativas de los migrantes adquirieron otra forma de pertenencia identitaria: el caravanero que migra, colectiviza todos sus repertorios sociales.

En los lugares donde se realizan estancias temporales, surge una necesidad de diversas actividades de cuidados (salud, educación, guardería), sobre todo de caravaneros que tienen menores a su cargo. Es cada vez más común la organización entre migrantes para la asistencia del cuidado de menores mientras los padres realizan trabajos para subsistir. Por ejemplo, en los últimos dos años, cinco de los veintinueve albergues de Tijuana brindan cuidado de niños a migrantes trabajadores (Coubès, Marie, et. al., 2020, p. 15). Han surgido también iniciativas binacionales como el programa piloto de las OSC Espacio Migrante y Create Purpuse, el cuál brinda clases educativas a la distancia para niñas y niños en espera de resoluciones de sus solicitudes de asilo (Morrisey, 2020: s/p).

Gran parte de estas caravanas -a las cuales se incorpora un número cada vez mayor de madres, mujeres embarazadas, niños y ancianos- son el reflejo de una realidad migratoria más compleja 
y radical debido a la actual etapa de transnacionalismo migratorio en Centroamérica, la cual se caracteriza por una demanda estructural de trabajo de cuidados en Estados unidos y la impronta necesidad de la reagrupación familiar de millones de migrantes centroamericanos que radican en este país.

A modo de contexto, según cifras de la ONU-Mujeres, la migración de mujeres centroamericanas a Estados Unidos se ha cuadruplicado entre 1990 y 2015, pasando de 491 mil a 1.37 millones de mujeres (2017, p. 26). En ese mismo periodo, las mujeres centroamericanas que participan en la población económicamente activa (PEA) en la Unión Americana se ha triplicado, y cerca de 1.03 millones de estas mujeres realizan trabajos relacionados con el cuidado (servicio doméstico, cuidado de menores, asistencia de adultos mayores, etcétera) (O'Connor, 2019). Otro dato que muestra la consolidación de las cadenas globales del cuidado es el incremento de remesas familiares en Centroamérica que entre 2000 y 2018 han pasado de 4,100 mdd a 22,300 mdd, respectivamente, creciendo a ritmos anuales promedio de $12 \%$ (CEPAL, 2019, p. 25).

Antes hemos mencionado que la migración de mujeres centroamericanas, que realizan trabajos del cuidado en Estados Unidos, ha provocado un reajuste en la distribución de las labores del cuidado en los lugares de origen. Los arreglos entre mujeres centroamericanas para el cuidado de menores -casi siempre precarios y marcados por relaciones de proximidad y/o poder- conllevan a un aumento significativo de circularidades migratorias de menores, y con ello, la consolidación de una estrategia transnacional de sobrevivencia a la que recurren cada vez más familias centroamericanas.

\section{Reflexiones finales}

El ciclo de caravanas migrantes que transitaron por México no ha terminado. En Honduras y Guatemala continúan convocatorias a nuevas caravanas por medio de redes sociales oponiéndose, quizás, al retorno a la transmigración clandestina, invisible y peligrosa de años anteriores.

Esto se debe a que las caravanas demostraron ser una innovadora estrategia de autocuidado migrante, pero, sobre todo, develaron una nueva forma de agencia política: los caravaneros que, migrando, ejercen su derecho inalienable a sostener sus vidas, defendiéndose de la violencia y la muerte que representa el régimen necrótico de control de fronteras en México.

El entrampamiento migratorio por territorio mexicano parece que perdurará a lo largo de los próximos años, por lo que estas estrategias de cuidados migrantes serán determinantes en la superación de las vulnerabilidades del tránsito. Los migrantes han decidido caravanear y colectivizar sus movilidades, no sólo por la seguridad que estas generan, sino porque politizan los espacios de tránsito al ocuparlos, mostrando el inalienable derecho de migrar para sobrevivir.

Las caravanas migrantes han abierto nuevos horizontes de posibilidad para interpretar los fenómenos migratorios, ya que muestran nuevas formas de agenciamiento social por la restitución de la dignidad de la vida, a partir del ejercicio de autonomía de los migrantes, pero, sobre todo, poniendo a los cuidados en el centro de estas movilizaciones.

Las caravanas continúan replicándose por todo el territorio mexicano, ahora con otros migrantes como la colectividad haitiana y sus interminables travesías que la diseminan por 
toda América Latina desde 2010. Hoy más que nunca, las estrategias de contención que ensayan todos los estados del corredor migratorio hacia Estados Unidos pueden ser interpeladas por estas redes de cuidados que sostienen la vida de los nómadas del siglo XXI.

\section{Referencias}

Anguiano, M. (2007). "Migración y mercado laboral en la frontera norte de México". En: Castillo, M. (Coord.) Nuevas tendencia y nuevos desafíos de la migración internacional. Memorias del Seminario Permanente sobre Migración Internacional. Tijuana: El Colegio de la Frontera Norte / Colegio de México. Disponible en: https://www.academia.edu/1894641/Migraci\%C3\%B3n_y_mercado_laboral_ en_la_frontera_norte_de_M\%C3\%A9xico_Nuevas_tendencias_y_nuevos_desaf\% C3\%ADos_de_la_ migraci $\% \mathrm{C} 3 \% \mathrm{~B} 3 \mathrm{n} \_$internacional

Babich, E. y Batalova, J. (2021). "Inmigrantes centroamericanos en los Estados Unidos. Migration Information Institute. Consultado el 9/12/2021. Disponible en: https://www.migrationpolicy.org/article/ inmigrantes-centroamericanos-en-los-estados-unidos\#distribuci $\% \mathrm{C} 3 \% \mathrm{~B} 3 \mathrm{n}$

Castillo, M. y Silvia P. (1999). "Central American International Emigration: trends and impacts". En: Appleyard, R. (ed.) Emigration dynamics in developing countries. Ciudad de México: CEPAL.

CEPAL (2019). Estudio económico de Centroamérica y la República Dominicana en 2018 y perspectivas para 2019. Ciudad de México: ONU-CEPAL.Consultado el 8/12/21. Disponible en: https://repositorio.cepal.org/ bitstream/handle/11362/44708/1/S1900618_es.pdf

Contreras, J. (2018). “Centroamérica: región de desplazamientos forzados”. En: López, N. (Ed.) Procesos migratorios en la Centroamérica del siglo XXI. Ciudad de México: UNAM

Coubès, M. et al. (2020). "Migrantes en albergues en las ciudades fronterizas del norte de México". Documentos de contingencia 2. Poblaciones vulnerables ante COVID-19. Tijuana: COLEF. Consultado el 10/12/21. Disponible en https://observatoriocolef.org/wp-content/uploads/2020/04/Albergues_w61_ compressed.pdf

De Genova, N. (2002). "Migrant 'Illegallity' a Deportability in Every Day”. Annual Review of Anthropology, 31: 419-447.

Del Monte, J. y Mckee, R. (2020) "Personas migrantes en Tijuana frente al COVID-19: Impactos y consecuencias de las medidas sanitarias desde la perspectiva de los actores". Documentos de contingencia. Poblaciones vulnerables ante COVID-19. Tijuana: COLEF. Consultado el 11/12/21. Disponible en https://www.colef.mx/estudiosdeelcolef/personas-migrantes-en-tijuana-frente-al-covid-19-impactosy-consecuencias-de-las-medidas-sanitarias-desde-la-perspectiva-de-los-actores/

Ernst, J. y Semple, K. (2019). "Las visas humanitaria en México: un imán para la nueva caravana migrante", The New York Times, del 25 de enero de 2019], Consultado el 10/12/21. Disponible en https://www.nytimes.com/es/2019/01/25/espanol/america-latina/mexico-migrantes-planatencion.html

González, M. (2021). "Caravana de migrantes: la violenta represión de Guatemala contra grupos que se dirigen caminando a EE.UU”, BBC News Mundo, del 19 de enero de 2021. Consultado el 10/12/21. Disponible en https://www.bbc.com/mundo/noticias-america-latina-55698861

González, E. (2011). Frontera vertical: México frente a los migrantes centroamericanos. Guadalajara: Centro Universitario UTEG.

Glenn, N. (2010). Forced to care: Coercion and caregiving in America. California: Berkeley University Press.

Glockner, V. (2019). "Las caravanas migrantes como estrategia de movilidad y espacio de protección, autonomía y solidaridad para los adolescentes centroamericanos". Revista Iberoforum. XIV (17): 145-174. Disponible en https://iberoforum.ibero.mx/index.php/iberoforum/article/view/126

Glockner, V. (2021). "Régimen de frontera y la política de separación de familias: racializacion y castigo de la migración forzada a través de cuerpos infantiles". En: Valdéz, M. y Narváez, J. (Coords.) \#Jóvenesymigración. El reto de converger: Agendas de investigación, políticas y participación. Ciudad de México: UNAM-SUDIMER. Disponible en: https://www.academia.edu/61970351/R\%C3\%A9gimen_de_ frontera_y_la_pol\%CC3\%ADtica_de_separaci $\% \mathrm{C} 3 \% \mathrm{~B} 3$ n_de_familias_racializaci $\% \mathrm{C} 3 \% \mathrm{~B} 3 \mathrm{n}$ _y_castigo_ de_la_migraci $\%$ C $3 \%$ B3n_forzada_a_trav $\%$ C $3 \% A 9$ s_de_los_cuerpos_infantiles

Hess, S. (2012). "De-naturalising Transit Migration. Theory and Methods of an Ehtnographic Regime Analysis". En: Smith, D. (Ed.) Population, Space and Place, 18: 428-440. 
134 Redes de cuidado frente al entrampamiento migratorio por COVID-19 en México

Mezzadra, S. (2007). Derecho de fuga. Migraciones, ciudadanía y globalización. Madrid: Traficantes de Sueños.

Mezzadra, S. (2012). "Capitalismo, migraciones y luchas sociales. La mirada de la autonomía". Revista Nueva Sociedad, 237: 159-178. Disponible en: https://nuso.org/articulo/capitalismo-migraciones-y-luchassociales-la-mirada-de-la-autonomia/

Morales, A. (2007). La diáspora de la posguerra. Regionalismo de los migrantes y dinámicas territoriales en América Central. San José: FLACSO.

Morrisey, K. (2020). "Los solicitantes de asilo varados en Tijuana y su lucha por sobrevivir en la pandemia". The San Diego Union-Tribune, del 1 de junio de 2020. Consultado el 13/12/21. Disponible en https:/ / www.sandiegouniontribune.com/ en-espanol/ noticias/inmigracion/articulo/2020-06-01/ solicitantes-de-asilocoronavirus-tijuana

O'Connor, A. et. al. (2019). "Inmigrantes centroamericanos en Estado Unidos". Migration Policy Institute. Consultado el 12/12/2021. Disponible en https://www.migrationpolicy.org/article/inmigrantescentroamericanos-en-los-estados-unidos-2017

ONU-Mujeres (2017). Situación de las mujeres trabajadoras migrantes. Síntesis analítica del Encuentro Internacional sobre la Situación de las Mujeres Trabajadoras Migrantes. Ciudad de México: El Colegio de México. Disponible en https://www2.unwomen.org/-/media/field $\% 20$ office $\% 20$ mexico/ documentos/publicaciones $/ 2017 / 08 / 2 \% 20$ mujeres $\% 20$ trabajadoras $\% 20$ migrantes.pdf?la $=$ es\&vs $=533$ 1

Ortega, A. (2015). "La migración de mujeres hondureñas y crisis de los cuidados". Revista Nueva Sociedad, 256: 103-113. Disponible en https://nuso.org/articulo/la-migracion-de-mujeres-hondurenas-y-la-crisis-delos-cuidados/

Parra, H. (2020). "Entrampamiento migratorio de centroamericanos en Tijuana, México". Revista (Trans)Fronteriza. La etnografía en los estudios de frontera, 1: 33-39. Disponible en: https://www.clacso.org/ boletin-1-transfronteriza-la-etnografia-en-los-estudios-de-frontera/

Pearce, J. (1998). "From Civil War to 'Civil Society': Has the end of the Cold War brought peace to Central America?". International Affairs, 74: 587-615.

Ramos, L. y Chio, Y. (2021). "Haitianos dejan campamento en Coahuila". Periódico La Jornada del 25/09/2021. Consultado el 10/12/2021. Disponible en: https://www.jornada.com.mx/notas/ 2021/09/25/politica/haitianos-dejan-campamento-en-coahuila/

Reina, E. (2021). "El laberinto de Tapachula, una cárcel a cielo abierto en la frontera sur". Periódico el País del 12/09/2021. Consultado el 10/12/2021. Disponible en: https://elpais.com/mexico/2021-09-12/ellaberinto-de-tapachula-una-carcel-a-cielo-abierto-en-la-frontera-sur.html

Sandoval, C. (2015). No más muros: exclusión y migración forzada en Centroamérica. San José: Editorial Universidad de Costa Rica.

Santamaría, G. (2007). "Maras y pandillas: límites de su transnacionalidad". Revista mexicana de política exterior, 81:101-123. Disponible en https://revistadigital.sre.gob.mx/images/stories/ numeros/n81/santamaria. pdf

Tronto, J. (2007). Un monde vulnérable. Pour une politique du care. París: La découverte.

U.S. Embassy (2019). "Estados Unidos implementa Protocolos de Protección a Migrantes en la frontera sur" del 29 de enero de 2019. Consultado el 09/12/21. Disponible en https://mx.usembassy.gov/es/estadosunidos-implementa-protocolos-de-proteccion-a-migrantes-en-su-frontera-sur/

Valencia, S. (2010). Capitalismo gore y necropolítica en México contemporáneo. España: Melusina.

Varela, A. (2015). “La 'securitización' de la gubernamentalidad migratoria mediante la 'externalización' de las fronteras estadounidenses a Mesoamérica". Revista Contemporánea, 4: 1-17. Disponible en: https://contemporanea.inah.gob.mx/del_oficio/amarela_varela_num4

Varela, A. y McLean, L. (2019). "Caravanas migrantes en México: nueva forma de autodefensa y transmigración”. Revista CIDOB d' Afers Internacionals, 122: 163-185. Disponible en: https://raco.cat/ index.php/RevistaCIDOB/article/view/10.24241-rcai.2019.122.2.163/452477

Varela, A. (2020). "Caravanas migrantes y refugiados centramericanos. Un feminismo para abrazar las fugas de quienes buscan preservar la vida". Revista Antropología Social, 29. (2): 245-255. Disponible en: https://revistas. ucm.es/ index.php/RASO/article/view/71669/4564456554586 